\title{
MDM2 SNP309 polymorphism is associated with lung cancer risk in women: A meta-analysis using METAGEN
}

\author{
WENWU HE $^{1^{*}}$, JIANXIONG LONG $^{2 *}$, LEI XIAN ${ }^{1}$, FENG PANG $^{3}$, \\ $\mathrm{LI} \mathrm{SU}^{2}$, SHIXIU WEI ${ }^{4}, \mathrm{BO} \mathrm{WEI}^{2}$ and YANLING HU ${ }^{4}$ \\ ${ }^{1}$ Department of Cardiothoracic Surgery, First Affiliated Hospital, Guangxi Medical University, Nanning, Guangxi; \\ ${ }^{2}$ School of Public Health, ${ }^{3}$ Fourth Grade of Clinical Medicine and ${ }^{4}$ Medical Research Center, \\ Guangxi Medical University, Nanning, Guangxi, P.R. China
}

Received March 29, 2012; Accepted June 15, 2012

DOI: $10.3892 /$ etm.2012.640

\begin{abstract}
Lung cancer is the most common diagnosed malignancy and the leading cause of cancer-related mortality worldwide. Murine double minute 2 (MDM2) SNP309 polymorphisms have been reported to influence the risk of lung cancer. However, the published studies together with four subsequent meta-analyses have yielded contradictory results. To examine this inconsistency, we conducted a meta-analysis of 6,696 lung cancer cases and 7,972 controls from eight published case-control studies using METAGEN. Odds ratios (ORs) with 95\% confidence intervals (CIs) were calculated with STATA software and used to assess the strength of the association. In the overall analysis, a significant association between MDM2 SNP309 polymorphism and lung cancer risk was observed (OR, 1.143; 95\% CI, 1.047-1.247). Moreover, stratified by ethnicity, a significant association was found in Asians (OR, 1.260; 95\% CI, 1.111-1.429), but not in Europeans. Subgroup analysis of gender, histology and smoking status suggested that the MDM2 SNP309 genotype was associated with increased lung cancer risk in women (OR, 1.282; 95\% CI, 1.062-1.548) and never smokers (OR, 1.328; 95\% CI, 1.119-1.575). No statistically significant association was observed in males and ever smoking population, and no association was found in subgroup analysis based on histology. In conclusion, the association between MDM2 SNP309 and lung cancer was statistically significant, particularly in Asians, women and never smoking population.
\end{abstract}

Correspondence to: Professor Bo Wei, School of Public Health, Guangxi Medical University, Nanning, Guangxi, P.R. China

E-mail: weibogx@163.com

Professor Yanling Hu, Medical Research Center, Guangxi Medical University, Nanning, Guangxi, P.R. China

E-mail: ylhupost@163.com

*Contributed equally

Key words: murine double minute 2, SNP309, polymorphism, lung cancer, meta-analysis

\section{Introduction}

Lung cancer is the most common malignancy diagnosed in males, and the fourth most common diagnosed malignancy in females worldwide. Moreover, it is the leading cause of cancer-related mortality in males and the second leading cause of cancer-related death in females. Based on the GLOBOCAN 2008 estimates, lung cancer accounts for $13 \%$ (1.6 million) of the total cases and 18\% (1.4 million) of deaths in 2008 (1). Lung cancer is a complex, multistage and multifactor disease. Smoking and environmental or occupational exposure may increase the risk of lung cancer; inherited polymorphisms including carcinogen metabolism (2), DNA damage and repair capacity (3), cell apoptosis (4) and cell-cycle control (5) also play important roles in determining interindividual variations in lung cancer susceptibility.

The murine double minute 2 (MDM2) gene located on chromosome 12q13-14 encodes an important negative regulator for the p53 tumor suppressor, resulting in its ubiquitination by direct binding to p53 (6). Apart from this critical function, $M D M 2$ overexpression may inhibit DNA repair independent of p53 (7,8). The carcinogenesis of MDM2 overexpression has been observed in various human tumors including lung (9-11), breast (12), bladder (13), gastric (14) and colorectal cancers (15).

An SNP (SNP309, T to G change at nucleotide 309) in the first intron of the MDM2 gene was identified and was found to be associated with an increased affinity for binding stimulatory protein SP1 to the promoter region, resulting in increased $M D M 2$ gene transcription and attenuation of the p53 pathway (16). Subsequently, several molecular epidemiological studies were conducted to assess the association between MDM2 SNP309 and lung cancer risk in Asians (10,17-19) Caucasians (9,20-22) and African-Americans (11). However, the results were not always consistent, possibly attributable to the fact that the majority of studies featured only a small number of samples or the association between the MDM2 SNP309 polymorphism and lung cancer risk did not achieve statistical significance. Two meta-analyses published in 2009 exploring the MDM2 SNP309 polymorphism and lung cancer risk yielded contradictory results $(23,24)$ and other two meta-analyses investigating MDM2 SNP309 and 
tumor susceptibility published in 2011 also showed inconsistent results $(25,26)$. To resolve these inconsistencies, we conducted the present meta-analysis of available case-control studies investigating the association between MDM2 SNP309 and lung cancer risk using METAGEN (27). In addition to performing subgroup analyses based on ethnicity and smoking status as the previous meta-analyses $(23,24)$, we conducted subgroup analyses involving gender and histology using the most appropriate genetic model.

\section{Materials and methods}

Search strategy. Pubmed, Embase and HuGENet databases were searched using the following terms or combinations: 'murine double minute 2', 'SNP309', 'MDM2', 'polymorphism' and 'lung cancer'. The search was conducted until February 2012, and was limited to English language studies. To obtain additional potentially eligible studies we also reviewed the reference lists of the original studies identified, as well as reviews and previous meta-analyses.

Inclusion and exclusion criteria. The eligible studies assessed in our meta-analysis had to achieve all of the following criteria: i) original studies concerning MDM2 SNP309 polymorphism and lung cancer risk, ii) studies containing useful genotype distribution information, iii) case-control or cohort studies and iv) studies with a control population without prior or current severe respiratory disease and malignant disease. The exclusion criteria were: i) studies analyzing the same patient population (the most recent or complete study was chosen) and ii) case-only studies, which were studies without a healthy control group.

Data extraction. From each eligible study, we extracted data consisting of the first author, year of publication, ethnicity of the population, the genotype frequency of the cases and controls, diagnostic criteria and genotyping methods. For studies including the the frequency of genotypes of the cases and controls according to different subgroups for gender, histology and smoking status, data were separately extracted for each subgroup whenever possible.

Statistical analysis. Hardy-Weinberg equilibrium (HWE) for the genotype distributions in the controls of each study was assessed using Pearson's Square ( $\mathrm{P} \geq 0.05)$ (28). Cochran's Q test (29) and the inconsistency index $\left(I^{2}\right)(30)$ were next calculated for assessment of heterogeneity. We considered $\mathrm{P}<0.05$ and $\mathrm{I}^{2}>50 \%$ to indicate significant heterogeneity $(31,32)$. In this case, we checked the data and statistical methods again, and conducted sensitivity analysis or subgroup analysis to analyze the reasons for heterogeneity. If significant heterogeneity was present, the random-effects model was used, or else, the fixed-effect model was chosen. Next, logistic regression analysis was performed to examine the association between the MDM2 SNP309 T>G polymorphism and lung cancer risk. Three genetic models: dominant (GG/TG vs. TT), recessive (GG vs. TG/TT) and co-dominant (GG vs. TG and TG vs. TT) were used to evaluated the risk. The methodology used to determine the most appropriate genetic model was reported by Bagos and Nikolopoulos (27). Two parameters $\theta_{2}$ and $\theta_{3}$ were calculated using the formula: $\log$ it $\left(\pi_{\mathrm{ij}}\right)=\alpha_{\mathrm{i}}+\theta_{2} \mathrm{z}_{\mathrm{i} 2}+\theta_{3} \mathrm{z}_{\mathrm{i} 3}$ and $\mathrm{OR}_{\mathrm{AB} / \mathrm{AA}}=\exp \left(\theta_{2}\right), \mathrm{OR}_{\mathrm{BB} / \mathrm{AA}}=\exp \left(\theta_{2}\right)$; where $\alpha_{\mathrm{i}}$ are indicators of the study-specific fixed-effects, and $\theta_{2}$ and $\theta_{3}$ are dummy variables of genotypes $\mathrm{AB}$ and $\mathrm{BB}$. The appropriate genetic model was identified using the following criteria (33):

i) no association: $\theta_{2}=\theta_{3}\left(\mathrm{OR}_{\mathrm{AB} / \mathrm{AA}}=\mathrm{OR}_{\mathrm{BB} / \mathrm{AA}}=1\right)$

ii) dominant model: $\theta_{2} \neq 0, \theta_{3} \neq 0$ and $\theta_{2}=\theta_{3}\left(\mathrm{OR}_{\mathrm{AB} / \mathrm{AA}}=\mathrm{OR}_{\mathrm{BB} / \mathrm{AA}} \neq 1\right)$

iii) recessive model: $\theta_{2}=0\left(\mathrm{OR}_{\mathrm{AB} / \mathrm{AA}}=1\right)$ and $\theta_{3} \neq 0\left(\mathrm{OR}_{\mathrm{BB} / \mathrm{AA}} \neq 1\right)$

iv) co-dominant model: $\theta_{2} \neq 0, \theta_{3} \neq 0$ and $2 \theta_{2}=\theta 3\left(\mathrm{OR}_{\mathrm{AB} / \mathrm{AA}}^{2}=\mathrm{OR}_{\mathrm{BB} / \mathrm{AA}}\right)$

Finally, once the most approtriate genetic model was identified, it was used to again pool the results for both logistic regression analysis and heterogeneity assessment. Subgroup analysis also abided by this procedure.

Publication bias was assessed using Egger's tests and Begg's funnel plot (34). The statistical analysis was performed using METAGEN (http://bioinformatics.biol.uoa.gr/ pbagos/ metagen/) and STATA version 11.1 (Stata Corporation, USA). All P-values were two-sided.

\section{Results}

Study inclusion and characteristics. According to the inclusion and exclusion criteria, we extensively searched the Pubmed, Embase and HuGENet databases. There were 14 original studies relevant to the associated of MDM2 SNP309 polymorphism and lung cancer risk retrieved. We reviewed all full-text studies intensively and excluded four studies without a control group (35-38). The study of Jun et al (39) was excluded since it included the same case and control population as Park et al (17). Finally, we excluded the study of Chua et al (19) since this study focused on the relevance between MDM2 SNP309 and lung cancer risk among non-smoking women, while the other studies included no gender and smoking state restriction. Thus, eight case-control studies (6,696 lung cancer cases and 7,972 controls) concerning the associated of the MDM2 SNP309 polymorphism and lung cancer risk were included in this meta-analysis $(9-11,17,18,20-22)$. The study of Pine et al (11) reported a population consisting of Caucasians and African-Americans, thus we recorded data on MDM2 SNP309 genotype distributions, respectively.

All of the eligible studies were consistent with HardyWeinberg equilibrium. The characteristics of the studies are summarized in Table I, and frequencies of the MDM2 309T>G polymorphism in the different populations are documented in Table II. Among these studies, some provided information on MDM2 SNP309 genotype frequencies in different subgroups based on gender, histology and smoking status (Table III).

Meta-analysis results. Table IV shows the detailed results of the heterogeneity test, assessment of the most appropriate genetic model, and the association between MDM2 SNP309 $\mathrm{T}>\mathrm{G}$ polymorphism and lung cancer risk evaluated using odds ratios (ORs) with 95\% confidence intervals (CIs). In the overall analysis, using the fixed-effect model, significant associations between the MDM2 SNP309 polymorphism and lung cancer risk were observed in the recessive model (OR, 1.143; 95\% CI, 1.047-1.247). Moreover, following the stratification of studies according to ethnicity, a statistically significant association was noted in Asian (OR, 1.260; 95\% CI, 1.111-1.429) while 


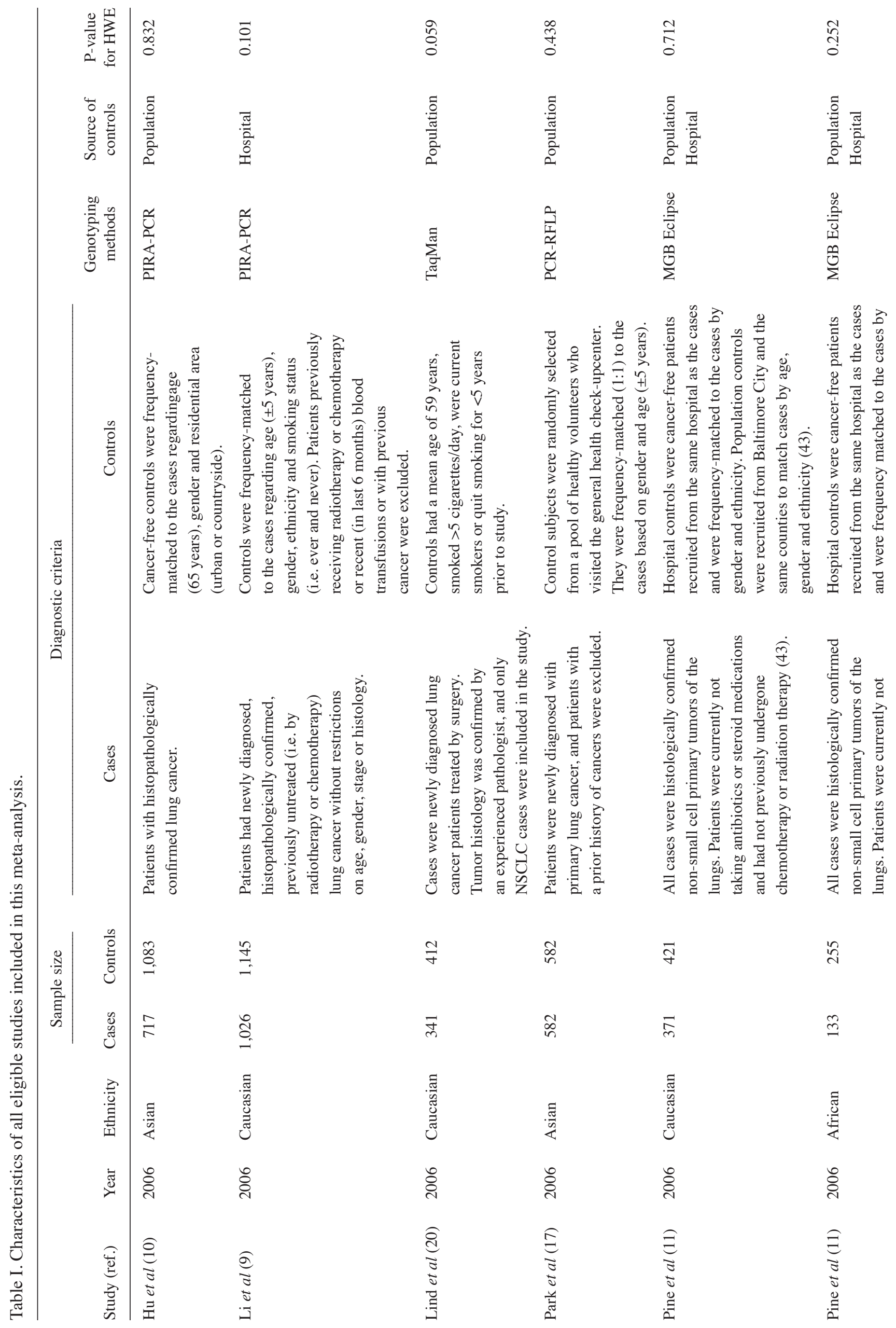




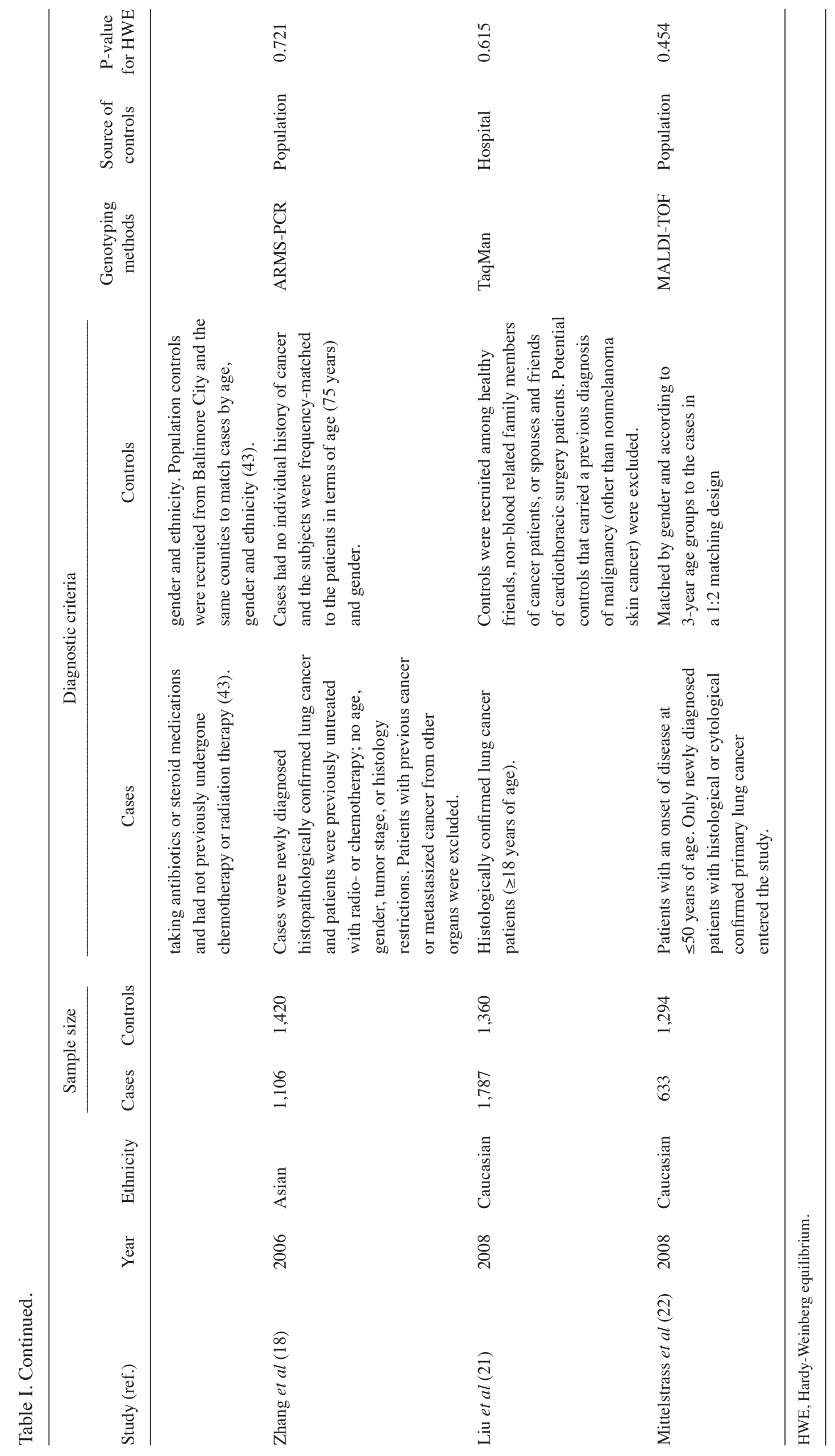


Table II. Frequency of the MDM2 309T>G polymorphism in the different populations.

\begin{tabular}{|c|c|c|c|c|c|c|c|c|}
\hline \multirow[b]{2}{*}{ Study (ref.) } & \multirow[b]{2}{*}{ Year } & \multirow[b]{2}{*}{ Ethnicity } & \multicolumn{3}{|c|}{ Cases } & \multicolumn{3}{|c|}{ Controls } \\
\hline & & & $\mathrm{TT}$ & TG & GG & TT & TG & GG \\
\hline Hu et al (10) & 2006 & Asian & 166 & 373 & 178 & 274 & 538 & 271 \\
\hline Li et al (9) & 2006 & Caucasian & 419 & 472 & 135 & 408 & 573 & 164 \\
\hline Lind et al (20) & 2006 & Caucasian & 130 & 156 & 55 & 161 & 207 & 44 \\
\hline Park et al (17) & 2006 & Asian & 113 & 280 & 189 & 122 & 299 & 161 \\
\hline Pine et al (11) & 2006 & Caucasian & 150 & 167 & 54 & 182 & 187 & 52 \\
\hline Pine et al (11) & 2006 & African-American & 111 & 20 & 2 & 203 & 47 & 5 \\
\hline Zhang et al (18) & 2006 & Asian & 249 & 561 & 296 & 418 & 711 & 291 \\
\hline Liu et al (21) & 2008 & Caucasian & 702 & 802 & 283 & 530 & 631 & 199 \\
\hline Mittelstrass et al (22) & 2008 & Caucasian & 270 & 293 & 70 & 547 & 598 & 149 \\
\hline
\end{tabular}

Table III. Frequency of the $M D M 2309 \mathrm{~T}>\mathrm{G}$ polymorphism in the different subgroups.

\begin{tabular}{|c|c|c|c|c|c|c|c|}
\hline \multirow[b]{2}{*}{ Subgroup } & \multicolumn{3}{|c|}{ Cases } & \multicolumn{3}{|c|}{ Controls } & \multirow[b]{2}{*}{ Study (ref.) } \\
\hline & $\mathrm{TT}$ & TG & GG & $\mathrm{TT}$ & TG & GG & \\
\hline \multicolumn{8}{|l|}{ Gender } \\
\hline Females & 191 & 230 & 63 & 215 & 294 & 78 & Li et al (9) \\
\hline Males & 228 & 242 & 72 & 193 & 279 & 86 & \\
\hline Females & 24 & 47 & 12 & 40 & 51 & 6 & Lind et al (20) \\
\hline Males & 106 & 109 & 43 & 121 & 156 & 38 & \\
\hline Females & 11 & 40 & 28 & 22 & 62 & 31 & Park et al (17) \\
\hline Males & 19 & 62 & 45 & 100 & 237 & 130 & \\
\hline Females & 346 & 381 & 139 & 302 & 362 & 91 & Liu et al (21) \\
\hline Males & 350 & 424 & 147 & 230 & 272 & 103 & \\
\hline Females & 95 & 103 & 30 & 197 & 232 & 50 & Mittelstrass et al (22) \\
\hline Males & 175 & 190 & 40 & 350 & 366 & 99 & \\
\hline \multicolumn{8}{|l|}{ Histology } \\
\hline Adenocarcinoma & 196 & 231 & 76 & 408 & 573 & 164 & Li et al (9) \\
\hline Squamous cell carcinoma & 98 & 98 & 28 & 408 & 573 & 164 & \\
\hline Adenocarcinoma & 30 & 102 & 73 & 122 & 299 & 161 & Park et al (17) \\
\hline Squamous cell carcinoma & 57 & 128 & 85 & 122 & 299 & 161 & \\
\hline Adenocarcinoma & 82 & 171 & 108 & 418 & 711 & 291 & Zhang et al (18) \\
\hline Squamous cell carcinoma & 113 & 241 & 122 & 418 & 711 & 291 & \\
\hline Adenocarcinoma & 422 & 475 & 158 & 530 & 626 & 204 & Liu et al (21) \\
\hline Squamous cell carcinoma & 178 & 186 & 59 & 530 & 626 & 204 & \\
\hline Adenocarcinoma & 98 & 98 & 25 & 547 & 598 & 149 & Mittelstrass et al (22) \\
\hline Non-small carcinoma & 382 & 415 & 130 & 408 & 573 & 164 & Li et al (9) \\
\hline Small cell carcinoma & 31 & 37 & 3 & 408 & 573 & 164 & \\
\hline Non-small carcinoma & 89 & 234 & 162 & 122 & 299 & 161 & Park et al (17) \\
\hline Small cell carcinoma & 24 & 46 & 27 & 122 & 299 & 161 & \\
\hline Non-small carcinoma & 183 & 205 & 50 & 547 & 598 & 149 & Mittelstrass et al (22) \\
\hline Small cell carcinoma & 70 & 67 & 16 & 547 & 598 & 149 & \\
\hline Non-small carcinoma & 130 & 156 & 55 & 161 & 207 & 44 & Lind et al (20) \\
\hline Non-small carcinoma & 702 & 802 & 283 & 530 & 631 & 199 & Liu et al (21) \\
\hline \multicolumn{8}{|l|}{ Smoking status } \\
\hline Ever & 357 & 385 & 112 & 332 & 482 & 146 & Li et al (9) \\
\hline Never & 62 & 87 & 23 & 76 & 91 & 18 & \\
\hline Ever & 650 & 735 & 253 & 362 & 419 & 125 & Liu et al (21) \\
\hline Never & 52 & 67 & 30 & 195 & 212 & 74 & \\
\hline Ever & 195 & 206 & 46 & 165 & 173 & 40 & Mittelstrass et al (22) \\
\hline Never & 71 & 77 & 21 & 369 & 413 & 105 & \\
\hline Ever & 19 & 61 & 45 & 94 & 228 & 122 & Park et al (17) \\
\hline Never & 11 & 41 & 28 & 28 & 71 & 39 & \\
\hline Ever & 172 & 338 & 182 & 255 & 377 & 141 & Zhang et al (18) \\
\hline Never & 77 & 223 & 114 & 193 & 334 & 150 & \\
\hline
\end{tabular}


Table IV. Meta-analysis of the MDM2 SNP309 T>G polymorphism in lung cancer.

\begin{tabular}{|c|c|c|c|c|c|c|}
\hline \multirow[b]{2}{*}{ Group } & \multirow[b]{2}{*}{$\mathrm{OR}_{\mathrm{AB} / \mathrm{AA}}(95 \% \mathrm{CI})$} & \multirow[b]{2}{*}{$\mathrm{OR}_{\mathrm{BB} / \mathrm{AA}}(95 \% \mathrm{CI})$} & \multirow[b]{2}{*}{ Genetic model } & \multirow{2}{*}{$\begin{array}{l}\text { OR }(95 \% \mathrm{CI}) \\
\text { of assumed } \\
\text { genetic model }\end{array}$} & \multicolumn{2}{|c|}{ Heterogeneity check } \\
\hline & & & & & P-value & $I^{2}$ \\
\hline Total & $1.003(0.931-1.081)$ & $1.144(1.037-1.262)$ & Recessive & $1.143(1.047-1.247)$ & 0.056 & $47.20 \%$ \\
\hline Caucasian & $0.932(0.850-1.022)$ & $1.024(0.896-1.170)$ & No association & & & \\
\hline Asian & $1.2(1.050-1.372)$ & $1.379(1.142-1.665)$ & Dominant & $1.260(1.111-1.429)$ & 0.145 & $48.30 \%$ \\
\hline \multicolumn{7}{|l|}{ Gender } \\
\hline Male & $0.927(0.817-1.053)$ & $0.948(0.796-1.131)$ & No association & & & \\
\hline Female & $0.939(0.815-1.082)$ & $1.239(1.011-1.519)$ & Recessive & $1.282(1.062-1.548)$ & 0.336 & $12.10 \%$ \\
\hline \multicolumn{7}{|l|}{ Histology } \\
\hline SCC & $0.936(0.779-1.124)$ & $1.039(0.796-1.358)$ & No association & & & \\
\hline $\mathrm{AC}$ & $0.991(0.870-1.130)$ & $1.204(0.959-1.512)$ & No association & & & \\
\hline SCLC & $0.842(0.653-1.086)$ & $0.723(0.501-1.043)$ & No association & & & \\
\hline NSCLC & $0.921(0.838-1.014)$ & $1.075(0.944-1.225)$ & No association & & & \\
\hline \multicolumn{7}{|c|}{ Smoking status } \\
\hline Never & $1.271(1.063-1.521)$ & $1.521(1.214-1.905)$ & Dominant & $1.328(1.119-1.575)$ & 0.151 & $40.50 \%$ \\
\hline Ever & $1.013(0.846-1.212)$ & $1.2(0.886-1.625)$ & No association & & & \\
\hline
\end{tabular}

All ORs were derived from random-effects model if the heterogeneity was statistically significant, or else, from the fixed-effects model. Logistic regression analysis and heterogeneity check were performed using the same genetic model. AC, adenocarcinoma; SCC, squamous cell carcinoma; NSCLC, non-small carcinoma; SCLC, small cell carcinoma.

not in European population. In the subgroup analysis based on gender, we found that the MDM2 SNP309 GG genotype conferred a statistically significant increased risk of lung cancer development in females (OR, 1.282, 95\%; CI, 1.062 1.548). However, we did not observe a similar result in males. In the subgroup analysis based on smoking status, a statistically significant association was observed in never smokers (OR, 1.328; 95\% CI, 1.119-1.575) but not in the ever smoking group. However, there was no evidence of a statistically significant association between the MDM2 SNP309 polymorphism and lung cancer risk in the subgroup analysis based on histology.

Publication bias. We performed Egger's test to access the publication bias. There was no indication that the shapes of the funnel plots exhibited obvious asymmetry, indicating any obvious evidence of publication bias in this meta-analysis.

\section{Discussion}

Previous meta-analyses elucidating the link between the MDM2 SNP309 polymorphism and lung cancer risk have provided discrepant results. Gui et al (24) found that the MDM2 309G allele is a low-penetrant risk factor for developing lung cancer in Asians, yet Bai et al (23) conducted a meta-analysis involved in the same research and found that the MDM2 SNP309 GG genotype enhanced the risk of lung cancer development in never smokers with statistical significance, but no statistically significant was noted in Asian and European individuals. The main difference between these two meta-analyses was the genetic model selection. Hence, we conducted the present metaanalysis, one study more than these two meta-analyses $(23,24)$ using METAGEN. Apart from finding that the MDM2 SNP309 polymorphism increases the risk of lung cancer development with a statistical significance, particularly in never smoking and Asian populations, we explored the relationships between the MDM2 SNP309 polymorphism and the risk of lung cancer based on subgroups of different gender and histology using the most appropriate genetic model. We detected a statistically significant association between the MDM2 SNP309 polymorphism and the risk of lung cancer in females.

According to the results of this meta-analysis, our main finding was that the MDM2 SNP309 polymorphism was statistically significantly associated with the risk of lung cancer in females but not in males. It appears that the results of the subgroup analysis according to females and males was due to smoking and no smoking status as more men smoke than women, and it has been suggested that MDM2 SNP309 increases the risk of lung cancer in never smokers $(21,23,40)$. Yet, this assumption counteracts with the traditional view that tobacco smoking causes lung cancer. We prefer to believe that the estrogen receptor $\alpha(\mathrm{ER} \alpha)$ regulates MDM2 SNP309 expression and leads to an increased risk of lung cancer in females. This indicates that men and women have approximately the same prevalence of lung cancer although smoking status tends to be higher among men compared to women.

The MDM2 SNP309 G allele frequency was found to be a risk factor in Asians. This result is consistent with previous studies $(17,18)$. The possible cancerogenic mechanism of the MDM2 SNP309 polymorphism was previously documented. However, the reason for the differential effects of the MDM2 polymorphism according to ethnicity is unclear. The differences in environment and genetic backgrounds may influence 
the association between the MDM2 SNP309 polymorphism and risk for lung cancer. Here, we must mention that, following subgroup analysis of Asian individuals, the result of our metaanalysis exhibited dissimilarity with Bai et al (23), which included the same studies conducted in Asians $(10,17,18)$. The main reason is the selection of the genetic model. We identified the most appropriate genetic model using METAGEN as described by Bagos and Nikolopoulos (27) and this method allowed for heterogeneity between studies, thus our results should be more accurate.

Heterogeneity is inevitable in a meta-analysis $(41,42)$. We have to admit heterogeneity also existed between all the included studies in our meta-analysis. Sources of heterogeneity may come from various channels. First, studies included in this meta-analysis were distributed according to different ethnicity and environment. In addition, a different methodology including the source of controls, diagnostic criteria and genotyping methods may lead to heterogeneity.

Other possible limitations should be taken into account which contributed to the low statistical power of this metaanalysis. For instance, we only selected studies published in the electronic edition of the databases in English language and ignored the studies published in other languages, in paper version or not published at all. Publication bias may exist although Begg's funnel plot and Egger's test did not detect bias. Additionally, not all the included studies contained the complete data needed particularly for the subgroup analysis, thus we only analyzed the obtained data.

In conclusion, the current meta-analysis demonstrates that the MDM2 SNP309 GG genotype may increase the risk of lung cancer particularly in Asians, females and never smoking population. Considering the limitations of this meta-analysis, further studies with large sample sizes, using well-designed and more accurate methods of genotyping are warranted to confirm the association between MDM2 SNP309 and lung cancer risk.

\section{Acknowledgements}

This study was supported by the Guangxi Natural Science Foundation (grant no. 0991116).

\section{References}

1. Jemal A, Bray F, Center MM, Ferlay J, Ward E and Forman D: Global cancer statistics. CA Cancer J Clin 61: 69-90, 2011.

2. Chiang HC, Wang CY, Lee HL and Tsou TC: Metabolic effects of CYP2A6 and CYP2A13 on 4-(methylnitrosamino)-1-(3-pyridyl)-1butanone (NNK)-induced gene mutation - a mammalian cell-based mutagenesis approach. Toxicol Appl Pharmacol 253: 145-152, 2011

3. Spitz MR, Wei Q, Dong Q, Amos CI and Wu X: Genetic susceptibility to lung cancer: the role of DNA damage and repair. Cancer Epidemiol Biomarkers Prev 12: 689-698, 2003.

4. Wang LE, Cheng L, Spitz MR and Wei Q: Fas A670G polymorphism, apoptotic capacity in lymphocyte cultures, and risk of lung cancer. Lung Cancer 42: 1-8, 2003.

5. Vonlanthen S, Heighway J, Kappeler A, Altermatt HJ, Borner MM and Betticher DC: p21 is associated with cyclin D1, p16INK4a and $\mathrm{pRb}$ expression in resectable non-small cell lung cancer. Int J Oncol 16: 951-957, 2000.

6. Brooks CL and Gu W: p53 ubiquitination: $\mathrm{Mdm} 2$ and beyond. Mol Cell 21: 307-315, 2006.

7. Alt JR, Bouska A, Fernandez MR, Cerny RL, Xiao H and Eischen CM: Mdm2 binds to Nbs1 at sites of DNA damage and regulates double strand break repair. J Biol Chem 280: 18771-18781, 2005.
8. Bouska A, Lushnikova T, Plaza S and Eischen CM: Mdm2 promotes genetic instability and transformation independent of p53. Mol Cell Biol 28: 4862-4874, 2008.

9. Li G, Zhai X, Zhang Z, Chamberlain RM, Spitz MR and Wei Q: MDM2 gene promoter polymorphisms and risk of lung cancer: a case-control analysis. Carcinogenesis 27: 2028-2033, 2006.

10. $\mathrm{Hu} \mathrm{Z}, \mathrm{Ma} \mathrm{H}, \mathrm{Lu} \mathrm{D}$, et al: Genetic variants in the MDM2 promoter and lung cancer risk in a Chinese population. Int J Cancer 118: 1275-1278, 2006.

11. Pine SR, Mechanic LE, Bowman ED, et al: MDM2 SNP309 and SNP354 are not associated with lung cancer risk. Cancer Epidemiol Biomarkers Prev 15: 1559-1561, 2006.

12. Ma H, Hu Z, Zhai X, et al: Polymorphisms in the MDM2 promoter and risk of breast cancer: a case-control analysis in a Chinese population. Cancer Lett 240: 261-267, 2006.

13. Onat OE, Tez M, Ozcelik T and Toruner GA: MDM2 T309G polymorphism is associated with bladder cancer. Anticancer Res 26: 3473-3475, 2006.

14. Ohmiya N, Taguchi A, Mabuchi N, et al: MDM2 promoter polymorphism is associated with both an increased susceptibility to gastric carcinoma and poor prognosis. J Clin Oncol 24: 4434-4440, 2006.

15. Alhopuro P, Ylisaukko-Oja SK, Koskinen WJ, et al: The MDM2 promoter polymorphism SNP309T-->G and the risk of uterine leiomyosarcoma, colorectal cancer, and squamous cell carcinoma of the head and neck. J Med Genet 42: 694-698, 2005.

16. Bond GL, Hu W, Bond EE, et al: A single nucleotide polymorphism in the MDM2 promoter attenuates the p53 tumor suppressor pathway and accelerates tumor formation in humans. Cell 119: 591-602, 2004.

17. Park SH, Choi JE, Kim EJ, et al: MDM2 309T >G polymorphism and risk of lung cancer in a Korean population. Lung Cancer 54: 19-24, 2006.

18. Zhang X, Miao X, Guo Y, et al: Genetic polymorphisms in cell cycle regulatory genes MDM2 and TP53 are associated with susceptibility to lung cancer. Hum Mutat 27: 110-117, 2006.

19. Chua HW, Ng D, Choo S, et al: Effect of MDM2 SNP309 and p53 codon 72 polymorphisms on lung cancer risk and survival among non-smoking Chinese women in Singapore. BMC Cancer 10: 88, 2010.

20. Lind H, Zienolddiny S, Ekstrom PO, Skaug V and Haugen A: Association of a functional polymorphism in the promoter of the MDM2 gene with risk of nonsmall cell lung cancer. Int J Cancer 119: 718-721, 2006.

21. Liu G, Wheatley-Price P, Zhou W, et al: Genetic polymorphisms of MDM2, cumulative cigarette smoking and nonsmall cell lung cancer risk. Int J Cancer 122: 915-918, 2008.

22. Mittelstrass K, Sauter W, Rosenberger A, et al: Early onset lung cancer, cigarette smoking and the SNP309 of the murine double minute-2 (MDM2) gene. BMC Cancer 8: 113, 2008.

23. Bai J, Dai J, Yu H, Shen H and Chen F: Cigarette smoking, MDM2 SNP309, gene-environment interactions, and lung cancer risk: a meta-analysis. J Toxicol Environ Health A 72: 677-682, 2009.

24. Gui XH, Qiu LX, Zhang HF, et al: MDM2 309 T/G polymorphism is associated with lung cancer risk among Asians. Eur $\mathbf{J}$ Cancer 45: 2023-2026, 2009.

25. Wan Y, Wu W, Yin Z, Guan P and Zhou B: MDM2 SNP309, gene-gene interaction, and tumor susceptibility: an updated meta-analysis. BMC Cancer 11: 208, 2011.

26. Wo X, Han D, Sun H, et al: MDM2 SNP309 contributes to tumor susceptibility: a meta-analysis. J Genet Genomics 38: 341-350, 2011.

27. Bagos PG and Nikolopoulos GK: A method for meta-analysis of case-control genetic association studies using logistic regression. Stat Appl Genet Mol Biol 6: Article 17, 2007.

28. Egger M, Davey Smith G, Schneider M and Minder C: Bias in meta-analysis detected by a simple, graphical test. BMJ 315: 629-634, 1997.

29. Midgette AS, Wong JB, Beshansky JR, Porath A, Fleming C and Pauker SG: Cost-effectiveness of streptokinase for acute myocardial infarction: A combined meta-analysis and decision analysis of the effects of infarct location and of likelihood of infarction. Med Decis Making 14: 108-117, 1994.

30. Higgins JP, Thompson SG, Deeks JJ and Altman DG: Measuring inconsistency in meta-analyses. BMJ 327: 557-560, 2003. 
31. Rose L SM, Cardwell CR, Jouvet P, McAuley DF and Blackwood B: Automated versus non-automated weaning for reducing the duration of mechanical ventilation for critically ill adults and children. Cochrane Database Syst Rev 7: CD009235, 2011. doi: 10.1002/14651858.CD009235.

32. Higgins JPT and Green S (eds): Cochrane Handbook for Systematic Reviews of Interventions, Version 5.1.0, updated March 2011. The Cochrane Collaboration, 2011. Available from www.cochrane-handbook.org.

33. Li H, Ha TC and Tai BC: XRCC1 gene polymorphisms and breast cancer risk in different populations: a meta-analysis. Breast 18 183-191, 2009.

34. Begg CB and Mazumdar M: Operating characteristics of a rank correlation test for publication bias. Biometrics 50: 1088-1101, 1994.

35. Heist RS, Zhou W, Chirieac LR, et al: MDM2 polymorphism, survival, and histology in early-stage non-small-cell lung cancer. J Clin Oncol 25: 2243-2247, 2007.

36. Han JY, Lee GK, Jang DH, Lee SY and Lee JS: Association of p53 codon 72 polymorphism and MDM2 SNP309 with clinical outcome of advanced nonsmall cell lung cancer. Cancer 113: 799-807, 2008.
37. Chien WP, Wong RH, Cheng YW, Chen CY and Lee $\mathrm{H}$ : Associations of MDM2 SNP309, transcriptional activity, mRNA expression, and survival in stage I non-small-cell lung cancer patients with wild-type p53 tumors. Ann Surg Oncol 17: 1194-1202, 2010.

38. Dong J, Ren B, Hu Z, et al: MDM2 SNP309 contributes to non-small cell lung cancer survival in Chinese. Mol Carcinog 50: 433-438, 2011.

39. Jun HJ, Park SH, Lee WK, et al: Combined effects of p73 and MDM2 polymorphisms on the risk of lung cancer. Mol Carcinog 46: 100-105, 2007.

40. Wan JT, et al: Meta-analysis of association between SNP309 in MDM2 promoter and lung cancer susceptibility. Chin J Cancer Prev Treat 5: 655-658, 2008 (In Chinese).

41. Higgins JP: Commentary: Heterogeneity in meta-analysis should be expected and appropriately quantified. Int J Epidemiol 37: 1158-1160, 2008

42. Groenwold RH, Rovers MM, Lubsen J and van der Heijden GJ: Subgroup effects despite homogeneous heterogeneity test results. BMC Med Res Methodol 10: 43, 2010. 